\title{
An exploratory pilot study on health education program to improve health literacy among female in their $20 \mathrm{~s}$
}

\author{
Shiho Kawata ${ }^{1^{*}}$ (1) and Emiko Saito ${ }^{2}$
}

\begin{abstract}
Objective: Health literacy $(\mathrm{HL})$ is one of the most important concepts in women's healthcare. The low cervical cancer screening rate for young Japanese women is an urgent issue. Cervical cancer is preventable, and cervical cancer screening behavior is associated with $\mathrm{HL}$. Therefore, the present study aimed to elucidate the effects of a health education program to improve HL among young female undergraduate students in Japan. Immediately after completing the program, participants evaluated their level of satisfaction with and the level of difficulty of the program, their understanding of the educational materials, and the length of the curriculum. Furthermore, 1 month after completing the program, participants evaluated their overall $\mathrm{HL}$ and their knowledge of women's health, and indicated whether they had undergone cervical cancer screening.

Results: Thirteen female undergraduate students in their 20 s participated. All participants indicated high levels of satisfaction and understanding of the material, and an appropriate level of difficulty of the curriculum. Three participants indicated that the program was too long. All participants had improved HL and knowledge of women's health after completing the education program, but no significant difference was observed in the cervical cancer screening rate.
\end{abstract}

Trial registration UMINR000036690 April 10, 2018 retrospectively registered

Keywords: Sex education program, Health literacy, Female undergraduate students

\section{Introduction}

Cervical cancer is the second most common cancer affecting females worldwide, with over 445,000 new cases and 270,000 deaths in 2012 [1]. The incidence of cervical cancer in Japanese women is 16.1 per 100,000 , and the rates of cervical cancer have steadily risen over the past 25 years [2]. Cervical cancer is preventable, but most women diagnosed with invasive cervical cancer have never or only rarely been screened [3]. The Ministry of Health, Labour and Welfare in Japan has been conducting screening for cervical cancer for women over 20 years of age since 2008 and recommends screening once every

\footnotetext{
*Correspondence: shkawata@kyotogakuen.ac.jp

${ }^{1}$ Department of Nursing, Faculty of Health and Medical Sciences, Kyoto Gakuen University, 18 Gotanda-cho, Yamanouchi, Ukyo-ku, Kyoto 615-8577, Japan

Full list of author information is available at the end of the article
}

2 years [4]. However, many Japanese women still never or rarely participate in such screenings. Health literacy (HL), which is the degree to which individuals have the capacity to obtain, process, and understand basic health information and services needed to make appropriate health decisions [5], is one of the most important concepts in women's healthcare for promoting such issues.

A previous systematic review concluded that HL explains cervical cancer screening behaviors [6]. Another study found that HL was low among Japanese adults [7], suggesting the importance of improving HL for Japanese people.

Education for the primary prevention of cervical cancer focusing on reducing the risk of human papillomavirus infection and transmission (along with other sexually transmitted infections [STIs]), tailored appropriately to age and culture, is currently provided to sexually healthy 
boys and girls [8]. However, fewer opportunities for sex education are provided to students after graduating from high school, and most such education in high school is inadequate [9]. Consequently, it is important for Japanese women in their 20 s to receive sex education including HL. The aim of the present study was to examine the effects of a health education program to improve women's HL among female undergraduate students in Japan.

\section{Main text}

\section{Methods}

\section{Research design and participants}

This study utilized a one-group pre-test/post-test quasi-experimental study design. The participants were recruited using posters placed in universities in Kyoto, Japan. The inclusion criteria were: (i) female undergraduate student; (ii) aged 20 years or older; and (iii) not a nursing, medicine, or pharmacy student. Data were collected from December 2014 to March 2015. The sample size was set to approximately 10 participants with reference to proceeding pilot studies of program development for cancer prevention $[10,11]$ and for healthy women $[12$, 13].

\section{Intervention program}

This program aimed to improve education for the prevention of cervical cancer, to reduce the risk for STIs, and to improve women's HL among female undergraduate students. The program was developed with reference to previous studies using skills training for condom use $[14,15]$ to improve HL education by using jargon-free communication, pictures to clarify concepts, and confirmation of participants' comprehension via the "showme" or "teach-back" method) [16] based on the opinions of female nurses and undergraduate students. The contents of the intervention program are shown in Table 1 . The program consisted of a group lecture and a demonstration (total $50 \mathrm{~min}$ ) to provide knowledge regarding the following: (i) using a basal body temperature thermometer and a vaginal discharge model to understand one's own menstrual cycle; (ii) using gynecological disease cases (e.g., endometriosis and STIs) to learn about recent trends in and the prevention of gynecological diseases; and (iii) using one's own smartphone to access health resources and worksheets regarding gynecological examinations and consultations. The teaching materials used in the program were created using Microsoft PowerPoint ${ }^{\circledR} 2013$ (Redmond, WA, USA). We also considered that audiovisual aids would allow us to watch the reactions of the participants during lectures. The literature review regarding HL and women's health suggested that readability, layout, and design were key components in developing effective printed materials [17],
Table 1 Contents of sex education program to improve $\mathrm{HL}$

\begin{tabular}{|c|c|}
\hline Contents & Materials \\
\hline 1. Knowing my body (20 min) & \multirow{11}{*}{$\begin{array}{l}\text { Slides delivered with presen- } \\
\text { tation software } \\
\text { A basal body thermometer } \\
\text { and graph } \\
\text { A vaginal discharge model } \\
\text { Using one's own smartphone } \\
\text { A worksheet simulating a } \\
\text { gynecological exam }\end{array}$} \\
\hline Basal body temperature & \\
\hline Menstrual periods & \\
\hline Vaginal discharge & \\
\hline $\begin{array}{l}\text { 2. Preventing gynecological disease } \\
\text { (20 min) }\end{array}$ & \\
\hline Sexually transmitted infections & \\
\hline $\begin{array}{l}\text { Communication about condom use } \\
\text { with partners }\end{array}$ & \\
\hline Cervical cancer screening & \\
\hline $\begin{array}{l}\text { 3. Gynecological exams and consultations } \\
\text { (15 min) }\end{array}$ & \\
\hline Overview of gynecological examination & \\
\hline How to select female health information & \\
\hline
\end{tabular}

$H L$ health literacy

so the illustrations used in the teaching materials and worksheets were done by a professional illustrator. The group lecture and demonstrations were conducted by a researcher and a public health nurse after providing an explanation of the study purpose and methods; both took place in the conference room of a public facility in Kyoto, Japan. The public health nurse had previous experience in maternal and child health practice.

\section{Evaluations}

We conducted an anonymous questionnaire survey and managed the data using concatenate numbers. Questionnaire items consisted of age, gynecological history, menstrual cycle, sex education history, and cervical cancer screening history. Test of knowledge for women's health was used to measure knowledge of women's health: the potential score range for this test was $0-20$ developed by the authors in reference to previous studies on women's health $[15,18,19]$. The level of satisfaction with the program, levels of difficulty and understanding of the educational materials and time required for the program were evaluated [20]. The main outcomes were HL score and percentage of cervical cancer screening behavior at 1 month after completing the program:

a) HL: HL scale for women in their 20s and 30s [21], in reference to a previous study on the development of an HL scale for Japanese [22], composed of 21 variables (score range, 21-84) organized into four subscales. The internal consistency between the four subscales varied (Cronbach's $\alpha, 0.75-0.83$ ).

b) Percentage of cervical cancer screening behavior: Whether the participants had attended a cervical cancer screening examination $(\mathrm{Y} / \mathrm{N})$ at 1 month after completing the program. 
Table 2 Characteristics of the participants $(n=13)$

\begin{tabular}{lc}
\hline Characteristics & Mean (SD) or n (\%) \\
\hline Age (years) & $20.7(0.4)$ \\
Gynecological history & \\
Yes & $4(30.8)$ \\
No & $9(69.2)$ \\
Menstrual cycle & \\
Regular & $4(30.8)$ \\
Irregular & $9(69.2)$ \\
Sex education history & \\
Elementary school & $1(7.7)$ \\
Junior high school & $2(15.4)$ \\
High school & $8(61.5)$ \\
University & $2(15.4)$ \\
Cervical cancer screening history & \\
Yes & $0(0.0)$ \\
No & $13(100.0)$ \\
\hline
\end{tabular}

$S D$ standard deviation

\section{Statistical analysis}

The data were analyzed using SPSS 23.0 for Windows (SPSS, Chicago, IL, USA). Statistical significance was set at $P<0.05$.

The results were analyzed by calculating basic statistics and pre-/post-comparisons of HL variables and knowledge using Wilcoxon's signed-rank test. Comparisons of the pre-/post-percentage of cervical cancer screening behavior were performed using McNemar's test, and the free descriptions were analyzed using content analysis.

\section{Ethical considerations}

Participants were informed of the study aims and methods and were assured that their participation would be voluntary and that every effort would be made to protect their privacy. We provided all materials used in the program to the participants.

\section{Results}

A total of 13 female undergraduate students (mean age, 20.7 years; standard deviation, 0.4; age range, 20-21 years) participated in the present study (Table 2).

All participants replied that their level of satisfaction with the program curriculum was either "very satisfied" or "satisfied", that the level of difficulty was "just right", and that the gynecological and educational materials were either "fully understood" or "understood". However, one participant replied that program's presentation slides were "difficult to see", and three participants replied that the program was "long". Many participants' felt that the program contents "observing vaginal discharge" and "undergoing a cervical cancer screening" were useful in their daily life, and the impressions (free comments) of the program included statements such as "I had found it difficult to ask about STIs, so I depended on information from the Internet" and "I now understand that women's health is important for a happy life".

HL and women's health knowledge were higher after the group lecture for all participants compared with before, but no significant differences were seen in pre-/ post-percentage of cervical cancer screening behavior (Table 3).

\section{Discussion}

The results of the present study showed that female undergraduate students had a high level of understanding and satisfaction regarding a health education program designed to improve HL. An earlier pilot study for women was considered feasible and acceptable if more than $75 \%$ reported being satisfied with its contents [23]. Using easy-to-understand electronic and printed materials can advance knowledge and understanding and lead to improved cancer screening rates [24]. In brief, this program is considered feasible and acceptable for female undergraduate students. In addition, it was found that participants urgently need more sex education and want to acquire more knowledge regarding gynecological diseases. Some proceeding studies in Asia reported that unmarried women, including female university students, have few opportunities regarding education for cervical cancer and the prevention of STIs, and that there is a shortage of knowledge on cervical cancer and STIs, including risk behaviors $[25,26]$. We suggest that the program provides a good opportunity for sex education and to improve HL among female undergraduate students. Only three participants $(23.1 \%)$ felt that the program was long. About $70 \%$ of Japanese university students have a part-time job to support the cost of living [27]. The present program was conducted in the evenings after the end of regular classes, a time at which such students may be busy. Therefore, securing time to attend a sex education program can be difficult. In the future, it will be necessary to shorten the length of the program and offer it at a time that is more accommodating to student schedules (e.g., during health checkups).

The results showed that this program improved HL and women's health knowledge among female undergraduate students. Some previous studies on HL and cervical cancer knowledge reported finding a relationship between cervical cancer and screening behaviors $[6,25,28]$. However, our results did not show any significant difference in the number of examinations after 1 month, so this program may not be effective in promoting participation in screening for cervical cancer. Our results suggest 
Table 3 Effects of the program to improve $\mathrm{HL}$ and cervical cancer screening behavior

\begin{tabular}{lccc}
\hline Variables & Pre-test $(\mathbf{n = 1 3 )}$ & Post-test $(\mathbf{n}=\mathbf{1 3})$ & P-value \\
\hline $\begin{array}{l}\text { HL scale }{ }^{\mathrm{a}} \text { (total) } \\
\text { Subscales }\end{array}$ & $58(56-63)$ & $68(59-79)$ & 0.001 \\
$\begin{array}{l}\text { Women's choice for adopting health information and } \\
\text { practice }\end{array}$ & $24(23-26)$ & $28(27-30)$ & 0.003 \\
Knowledge of female body & $15(14-16)$ & $17(15-20)$ & 0.004 \\
Self-care during menstruation & $13(10-15)$ & $15(13-17)$ & 0.003 \\
Sexual discussion with partner & $6(4-7)$ & $18(17-8)$ & 0.023 \\
Test of knowledge for women's health & & & 0.003 \\
Cervical cancer screening behavior & $16(13-18)$ & $4(30.8)$ & 0.125 \\
Yes & $0(0.0)$ & $9(69.2)$ & \\
No & $13(100.0)$ & \\
\hline
\end{tabular}

HL health literacy

a Wilcoxon's signed-rank test; data are expressed as median (interquartile range)

b McNemar's test and this question were conducted at 1 month after completing the program

that the timing of evaluation of cervical cancer screening behavior was early, and thus, a methodological review is necessary.

A systematic review concluded that there were a number of barriers to participation in cervical cancer screening examinations, such as inaccessible clinics and inconvenient locations and appointment times [29]. The low cervical cancer screening rate among women in Japan is an urgent issue, and a health care system that provides unmarried women with access to such screenings without causing a psychological or physical burden is needed. As the average age at first marriage for Japanese women (31.1 years as of 2015) is increasing [30], we believe that the number of sexually experienced unmarried women is also increasing. Therefore, it is important to improve sex education tailored as appropriate to age and culture. In the future, it will be necessary to further consider the length and duration of the present program in greater detail. In conclusion, to the best of our knowledge, this is the first study in Japan to focus on improving HL in relation to women's health. The findings are expected to improve HL in relation to women's health among young Japanese women.

\section{Limitations}

This study used a one-group pre-test/post-test quasiexperimental design. A study that sets a sample size with reference to the HL scores from the present study and compares HL scores with a different group needs to be conducted. The study participants were female undergraduate students likely to be interested in women's health, but support is needed for all women, not only those interested in women's health. Some unknown factors affect HL. Few HL studies in relation to nursing in Japan have been conducted, and some factors related to HL remain unclear; therefore, unknown related factors other than the factors used in the present study could have affected the results.

\section{Abbreviations}

HL: health literacy; STIs: sexually transmitted infections.

\section{Authors' contributions}

SK and ES conceived of the study conception and study design; SK collected the data; SK and ES analyzed and interpreted the data; SK and ES were involved in drafting and critically revising the manuscript for important intellectual content. All authors read and approved the final manuscript.

\section{Author details}

${ }^{1}$ Department of Nursing, Faculty of Health and Medical Sciences, Kyoto Gakuen University, 18 Gotanda-cho, Yamanouchi, Ukyo-ku, Kyoto 615-8577, Japan. ${ }^{2}$ Department of Nursing Sciences, Graduate School of Human Health Sciences, Tokyo Metropolitan University, 7-2-10 Higashi-Ogu, Arakawa-ku,

Tokyo 116-8551, Japan.

\section{Acknowledgements}

We wish to thank all the study participants. We would also like to express our gratitude to the associates of the Graduate School of Human Health Science, Tokyo Metropolitan University.

\section{Competing interests}

The authors declare that they have no competing interests.

\section{Availability of data and materials}

All data generated or analyzed during the present study are included in this published article.

\section{Consent for publication}

Not applicable.

\section{Ethics approval and consent to participate}

This study was conducted after obtaining the approval of the 2014 Research Safety and Ethics Committee of the Tokyo Metropolitan University Arakawa Campus (Approval No. 14083). We informed all participants both verbally and in writing about the purpose of this study and assured all participants that their personal information would be protected. We also informed them 
that their participation in the present study was voluntary. All participants provided written consent to participate in this study. Clinical trial registration UMINR000036690 April 10, 2018, retrospectively registered.

\section{Funding}

This study was supported by JSPS KAKENHI for Young Scientists (B), Grant Number 15K20801.

\section{Publisher's Note}

Springer Nature remains neutral with regard to jurisdictional claims in published maps and institutional affiliations.

Received: 17 April 2018 Accepted: 6 August 2018

Published online: 13 August 2018

\section{References}

1. Cancer Today, Fact Sheet, IARC. http://gco.iarc.fr/today/fact-sheets-cance $r$ s? cancer $=16 \&$ type $=0 \&$ sex $=2$. Accessed 28 Feb 2018 .

2. Graph Data Base, Cervix Uteri by Cancer, Cancer Information Service, National Cancer Center, Japan. http://gdb.ganjoho.jp/graph_db/index ?changeLang=Submit. Accessed 28 Feb 2018.

3. Spence AR, Goggin P, Franco EL. Process of care failures in invasive cervical cancer: systematic review and meta-analysis. Prev Med. 2007;45:93-106

4. Guidelines for priority education of cancer prevention and the implementation of cancer screening, Ministry of Health, Labour and Welfare in Japan. http://www.mhlw.go.jp/stf/seisakunitsuite/bunya/0000059490 .html. Accessed 28 Feb 2018 (in Japanese).

5. Berkman ND, Davis TC, McCormack L. Health literacy: what is it? J Health Commun. 2010;15(Suppl 2):9-19.

6. Kim K, Han HR. Potential links between health literacy and cervical cancer screening behaviors: a systematic review. Psychooncology. 2016;25:122-30.

7. Tokuda Y, Okubo T, Yanai H, Doba N, Paasche-Orlow MK. Development and validation of a 15-item Japanese health knowledge test. J Epidemiol. 2010;20:319-28.

8. World Health Organization. Comprehensive cervical cancer control: a guide to essential practice. 2nd ed. http://apps.who.int/iris/bitst ream/10665/144785/1/9789241548953_eng.pdf?ua=1. Accessed 28 Feb 2018

9. Shikama K, Iwasaki Y, Nakamura C, Tokita E, Sako K. A study of measures to promote sexual education by yogo teachers in high school. Adolescentology. 2014;32(4):388-403 (in Japanese).

10. Pruthi S, Stange KJ, Malagrino GD Jr, Chawla KS, Larusso NF, Kaur JS. Successful implementation of a telemedicine-based counseling program for high-risk patients with breast cancer. Mayo Clin Proc. 2013;88:68-73.

11. Hongguang D, Frank L, Isabelle C, Aldo C, Patrick G, Paul B. An exploratory pilot study of acupuncture on the quality of life and reproductive hormone secretion in menopausal women. J Altern Complement Med. 2001;7(6):651-8.

12. Beddoe AE, Lee KA, Weiss SJ, Keneddy HP, Yang CP. Effects of mindful yoga on sleep in pregnant women: a pilot study. Biol Res Nurs. 2010;11(4):363-70.

13. Miyako Y, Hiromi E. Development and process evaluation of a breast awareness program. J Jpn Acad Midwifery. 2010;24(2):375-85 (in Japanese)

14. Kessler TA. Increasing mammography and cervical cancer knowledge and screening behaviors with an educational program. Oncol Nurs Forum. 2012:39:61-8
15. Choi KH, Hoff C, Gregorich SE, Grinsread O, Gomez C, Hussey W. The efficacy of female condom skills training in HIV risk reduction among women: a randomized controlled trial. Am J Public Health. 2008;98:1841-8.

16. Kountz DS. Strategies for improving low health literacy. Postgrad Med. 2009;121(5):171-7.

17. Corrarino JE. Health literacy and women's health: challenges and opportunities. J Midwifery Womens Health. 2013;58:257-64.

18. Champion JD, Harin B, Collins JL. Sexual risk behavior and STI health literacy among ethnic minority adolescent women. Appl Nurs Res. 2013;26:204-9.

19. Sandfort JR, Pleasant A. Knowledge, attitudes, and informational behaviors of college students in regard to the human papillomavirus. J Am Coll Health. 2009:58:141-9.

20. Hawe P, Degeling D, Hall J. What to measure first: process evaluation: evaluation health promotion. 1st ed. New South Wales: MacLennan \& Petty Pty Limited; 1990.

21. Kawata S, Hatashita H, Kinjo Y. Development of a health literacy scale for women of reproductive age an examination of reliability and validity in a study of female workers. Nihon Koshu Eisei Zasshi. 2014;61(4):186-96 (in Japanese)

22. Suka M, Odajima T, Kasai M, Igarashi A, Ishikawa H, Kusama M, Nakayama T, Sumitani M, Sugimori $H$. The 14-item health literacy scale for Japanese adults (HLS-14). Environ Health Prev Med. 2013;18:407-15.

23. Soto-Perez-de-Celis E, Smith DD, Rojo-Castillo MP, Hurria A, Pavas-Vivas AM, Gitler-Weingarten R, Mohar A, Chavarri-Guerra Y. Implementation of a school-based education program to increase breast cancer awareness and promote international transmission of knowledge in a rural Mexican community. Oncologist. 2017;22:1249-56.

24. Simmons RA, Cosgrove SC, Romney MC, Plumb JD, Brawer RO, Gonzalez ET, Fleisher LG, Moore BS. Health literacy: cancer prevention strategies for early adults. Am J Prev Med. 2017;53(3S1):S73-7.

25. Dhendup T, Tshering P. Cervical cancer knowledge and screening behaviors among female university graduates of 2012 attending national graduate orientation program, Bhutan. BMC Womens Health. 2014;14:44

26. Koketsu Y, Kaneko N, Ishikawa S. Comparison of STI-related sex behavior and access to STI-related information of women between when they were 19 years old and present age. WHS. 2014;13:53-61 (in Japanese).

27. Campus Life Data 2017. National federation of university co-operation associations. http://www.univcoop.or.jp/press/life/report.html. Accessed 28 Feb 2018 (in Japanese)

28. Son YJ, Kim SH, Kim GY, Son H. Associations between health literacy, cancer-related knowledge, and preventive health behaviors in community dwelling Korean adults. J Health Commun. 2017;22:999-1006.

29. Chorley AJ, Marlow LA, Forster AS, Haddrell JB, Waller J. Experiences of cervical cancer screening and barriers to participation in the context of an organized programme: a systematic review and thematic synthesis. Psychooncology. 2017;26:161-72.

30. Marriages 2015. Vital statistics in Japan. https://www.e-stat.go.jp/en. Accessed 28 Feb 2018.

Ready to submit your research? Choose BMC and benefit from

- fast, convenient online submission

- thorough peer review by experienced researchers in your field

- rapid publication on acceptance

- support for research data, including large and complex data types

- gold Open Access which fosters wider collaboration and increased citations

- maximum visibility for your research: over $100 \mathrm{M}$ website views per year

At $\mathrm{BMC}$, research is always in progress.

Learn more biomedcentral.com/submissions 